\title{
BMJ Open Quality Nurse-managed transitional beds as a method of increasing geographic placement of an academic inpatient service
}

\author{
Christopher W Goodman
}

To cite: Goodman CW. Nursemanaged transitional beds as a method of increasing geographic placement of an academic

inpatient service.BMJ Open Quality 2017;6:e000078.

doi:10.1136/

bmjoq-2017-000078

Received 6 April 2017 Revised 4 October 2017 Accepted 5 October 2017
CrossMark

Department of Medicine, University of South Carolina School of Medicine, Columbia, South Carolina, USA

Correspondence to Dr Christopher W Goodman; cgoodman@uscmed.sc.edu

\section{ABSTRACT}

Geographic placement of patients in hospitals has long been valued to bring together all healthcare members as a team focused on high-quality patient-centred care. This goal can be particularly challenging for physicians whose patients are often scattered across various hospital units. The inpatient medicine service for the Palmetto HealthUniversity of South Carolina Internal Medicine Residency Program began attempting geographic placement when a model for team-based care was adopted in 2015, but despite various process improvements we found it very difficult to maintain a high census of our patients on the unit. We eventually came up with an innovative solution to the problem that incorporated the use of transition beds - beds dedicated for patients moving onto or out of the unit in order to make it easier for the unit to control patient flow. We saw an immediate increase in our average census from $\sim 8$ to $\sim 15$ patients as well as a major shift of the median admission time to 3.5 hours earlier in the day. Unfortunately, it was an added burden to our already stressed charge nurses, and when the pilot ended we were forced to end the use of the transition beds. Despite our challenges, we applied valuable lessons learnt that have helped us in other improvement projects, and overall we did successfully demonstrate that transition beds are a viable option for an inpatient medical unit to improve geographic placement of patients while optimising patient flow.

\section{PROBLEM}

Teamwork is an ideal that is considered central to the practice of healthcare, but not often explicitly encouraged or facilitated through the organisation of healthcare. Modern trends like the patient-centred medical home seek to remedy that. Within hospitals, there are numerous challenges to building unified teams including the at times competing needs of moving patients quickly through the system and placing them in the right bed. There are now entire seminars and conferences devoted to the challenge of 'throughput' or 'hospital flow'. As the pace speeds up and complexity of hospital care builds, it becomes much more challenging yet vitally important to foster good teamwork.
Palmetto Health Richland in Columbia, $\mathrm{SC}$, is the training site for the Palmetto Health/University of South Carolina Internal Medicine Residency Program (USC IM). In November 2015, USC IM began team-based care on 10 East (10E) based on the accountable care unit (ACU) model, ${ }^{1}$ which included geographical placement of USC IM patients on 10E. There are 29 beds on the unit, four of which were closed at the time of this project due to nurse staffing levels. The two USC IM inpatient teams, due to various institutional constraints, should have been able to be responsible for about 20 of the 25 patients.

Over the first few months of geographic placement on 10E, we continued to have difficulty with correct initial placement of our patients. Our average total census on $10 \mathrm{E}$ was about eight patients ( $\sim 30 \%$ of beds) despite having administrative staff dedicated to make sure admitted patients went to the correct unit. The problem has been primarily about emergency department (ED) flow-once an appropriate type of bed opens up in the hospital there is pressure for the patient to move immediately to that bed rather than wait for a specific unit like $10 \mathrm{E}$ to have a bed. This is especially true for general medicine patients who can go most anywhere in the hospital unlike some services that require specific training for nurses like orthopaedics, trauma and stroke units.

Given the ideals of team-based care and quality improvement (QI) could only be met if our patients were located on $10 \mathrm{E}$, we began brainstorming solutions. Our overall goal was to increase appropriate and timely placement of USC IM patients on 10E without significantly impeding ED flow. Our specific aim was to increase our patient census to 16-18 patients within 1 month.

\section{BACKGROUND}

While there is developing literature around the benefits of geographic placement and 
the ACU model, limited information exists on how units and medical teams are able to maintain geographic placement. There has also been much written about how EDs and hospitals can improve patient flow with most of the examples revolving around teams dedicated to discussing flow challenges and assigning staff to help bridge the placement challenges among units. ${ }^{2}$

The challenge is that patient throughput is a complex, interdependent process of many variables across a hospital system. If our patients wait longer in the ED for a bed, that could contribute to a backlog in the ED, delayed care for other patients and potentially worse health outcomes. ${ }^{2}$ For good reason, measurement of ED flow will soon be a part of how hospitals are measured on their quality of care, and this will only increase the pressure for hospitals to ensure patients are moved out of the ED in a timely fashion. ${ }^{3}$

The hospital system was in the process of implementing an interdepartmental team to look at hospital flow and also had hired staff to help connect patients to the right units. Our unit began looking at ways to fine-tune our own process of identifying patients moving onto or off the unit as well as designing a system to pull patients to our unit in a way that would not be burdensome for either unit staff or the ED.

\section{MEASUREMENT}

Our main goal was to increase the census of USC IM on $10 \mathrm{E}$. This would be tabulated as a run chart with a daily spot check of the census each morning. The average had been at eight patients total per day or $\sim 30 \%$ of available beds on the unit. We knew other throughput measures would be important to track such as ED hold times and time of admission to 10E. Our admissions historically had been later in the day, and we knew that later admissions could cause potential problems with the handover at nursing shift change.

The nurse manager and medical director also gathered qualitative information about the satisfaction of our patients and staff throughout the process changes.

Run charts were converted into control charts; specifically, XMR charts were used. The data were analysed together and special cause variation noted.

\section{DESIGN}

Our unit leadership was consistently attempting to address geographic placement in monthly unit and interdepartmental QI meetings. We had corrected several contributing factors of patient throughput (eg, order sets, communication about new admissions, patient navigator communication), but the problem of a low census persisted. Staff in the department of patient placement knew of the goal to place USC IM patients on $10 \mathrm{E}$, but despite ongoing assurances that new processes were being attempted many of our patients were still being placed elsewhere. Our team considered various options and ultimately decided to focus on how our unit could

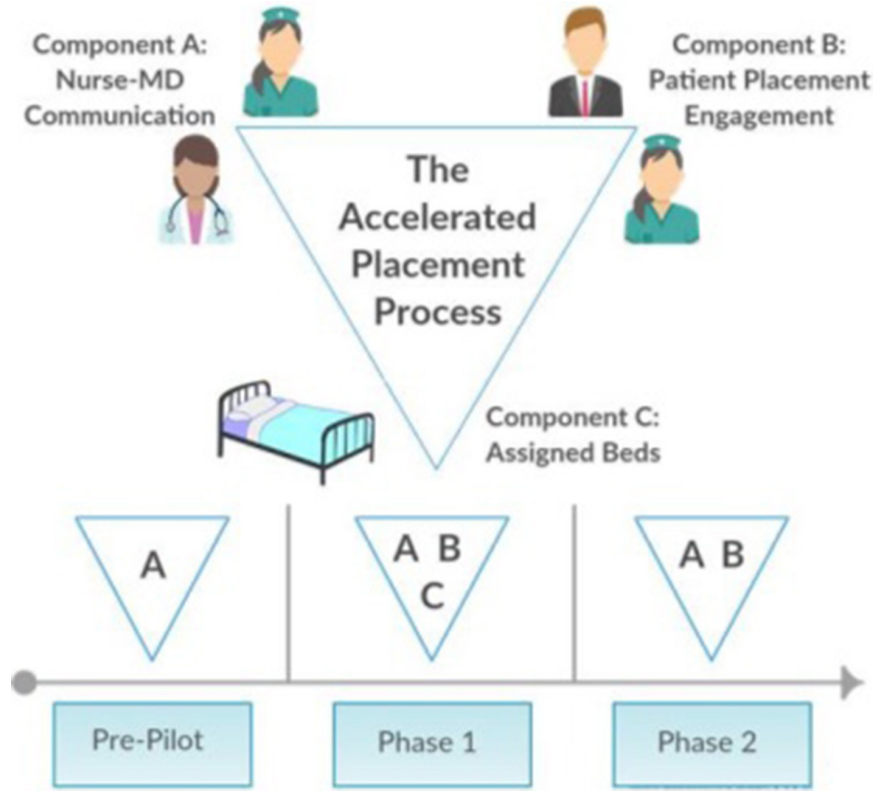

Figure 1 Framework for the accelerated placement process (APP) and timeline for integration of various components. Phase 1 was a fully realised vision of the APP as it incorporated all components. A-Nurse-MD communication: each day the charge nurse and the senior resident for each team collaboratively make a list of potential discharges, admissions and transfers. B-Patient placement engagement: we empowered the charge nurses to maintain regular communication regarding patient flow and to assert more control especially over the assigned beds for patients in transition. This involved use of teletracking software and direct messaging. $\mathrm{C}-$ Assigned beds: two semiprivate rooms (four beds) were identified to be managed by the charge nurse in order to facilitate moving people onto or off the unit. The room was staffed with a dedicated nurse and nurse extender. MD, medical doctor.

pull patients rather than passively receiving them, which eventually led to us considering how to assign specific beds as transition beds.

We assembled a diverse design team tasked with solving how we might be able to control some of our own beds for placement purposes. Representation was broad and included leadership from 10E, patient placement, nursing and USC IM. The following were team members: Jaycelyn Morant (10E nurse manager), Christopher Goodman (10E medical director), Forrest Fortier, Harmony Robinson, Pate Cox (patient placement manager), Levi Campbell, Twanna Pretty, Lisa Houghton, Mike Rawl (administrative medicine) and Lisa James (director of nursing). The team met for about 2 months prior to launch for planning and ultimately developed the framework for the accelerated placement process (APP) shown in figure 1 .

The APP consisted of three components: (1) daily nurse-medical doctor (MD) communication to identify patients appropriate for transfer to the unit or needing to leave the unit, (2) patient placement engagement and (3) transition beds available for moving patients into or out of the unit. The structured daily nurse-MD communication 
(component A in figure 1) involved maintaining an electronic list of patients needing to move onto or off the unit. This was a PDSA (plan-do-study-act) cycle that started 2 months prior to the pilot and sustained throughout the improvement process. The period of this intervention prior to the APP pilot is labelled as the prepilot phase in figure 1. It was during this intervention period that we realised our strategy needed to shift.

The role of patient placement engagement (component B) while seemingly nebulous was still considered to be worth noting as a factor in the design process. While the unit nurses had in the past communicated daily with this department in the course of their work, this was really the first time we were all sitting down together to work towards a shared goal of correct placement of our patients. This relationship building, crucial in culture change, could itself have an impact on the placement of our patients and so was considered an additional component still technically in place after we discontinued the transition beds.

The full APP pilot involving all components was planned for 1 month beginning 17 July 2016. During this phase (phase 1 in figure 1), an additional nurse and nurse extender were made available to the unit in order to manage the four additional beds as a transitional suite; total open beds increased from 25 to the maximum of 29 . Nursing administrative support was provided to help unit management and charge nurses plan nurse schedules with the additional staffing support. Instead of assigning nurses to these transition beds and creating the problem of an additional handoff, we opted for the admitting nurse to follow their patient on the move to another $10 \mathrm{E}$ bed.

At the end of the pilot, the additional staffing support ended. We returned to 25 beds and made the decision not to continue the transition suite component of the APP. The reasons are discussed below. In the spirit of improvement, we considered it an opportunity to assess the importance of the transition beds. This postpilot period is labelled as phase 2 in figure 1.

\section{STRATEGY}

Knowing that the charge nurses were the conduits of information for throughput on the unit and the residents held the information about potential discharges or transfers of non-10E USC IM patients, we ran a PDSA cycle on daily structured communication between the charge nurse and senior residents for several months prior to the start of the full APP model. Each day at 08:00, the two senior residents and charge nurse for the day would discuss potential transfers, ED admits and discharges. This would help the charge nurse prioritise throughput on the unit. While this structured communication had some logic and it did help with perceptions of improved communication on our unit, it did not meaningfully change our census. We thought this was likely because the culture remained in place within the hospital to move patients out of the ED as soon as possible, regardless of requests by our unit.

We decided we needed to be more involved in the patient placement process and perhaps even have control over some of our beds for this purpose. This led to the design team formation and the APP process described above. The heart of the APP was the transition suite with certain beds set aside for patients moving into or out of the unit-that is, transfers, admissions or pending discharges. This complex intervention required extensive planning, which took about 2 months.

After the pilot period of 1 month ended, we were forced to close the four transition beds and return to previous staffing levels. It was an opportunity to assess the importance of the transition beds since they had to be closed but the same structured communication and ongoing patient placement relationship remained in place.

\section{RESULTS}

While we did not meet our initial aim of 16-18 patients, we did see our census more than double to $\sim 15$, or $50 \%$ of the unit; very close to our target. As noted in the control chart in figure 2, there was an immediate increase in our census that coincided nicely with the opening of the beds for use as a transition suite (phase 1). This honeymoon period was followed about 2 weeks later by a notable dip in our census, which coincided with a visit from The Joint Commission (TJC). This confirmed anecdotal evidence that these visits reinforce the pressure to decompress the ED. It is interesting to note that the census never fully recovered during the rest of the phase 1 period.

Despite the loss of assigned beds and reduction in staffing for phase 2, there was an apparent increase back to early phase 1 levels prior to the TJC visit. We attributed this to an ongoing enthusiasm on the part of charge nurses and relationship with patient placement to help maintain the high census. This was short lived, however, as the census declined again after the following weekend. Over subsequent months, the census continued to decline. Since the pilot ended, we were never able to return to the use of the transition suite and have only continued the structured nurse-MD communication. As of this writing, months after the pilot ended, the census has again been around eight patients.

We also looked at important secondary measures including median admit time to $10 \mathrm{E}$, patient and staff experience, and ED hold times. ED hold times for patients admitted to $10 \mathrm{E}$ decreased from 11.6 hours per patient to 10.7 hours without affecting the overall ED hold times. Figure 3 shows the shifts in median admission time to $10 \mathrm{E}$ that correspond nicely to the different phases. The median admit time prepilot was 17:24, which caused a significant headache for the evening nurse shift change. This shifted 3.5 hours earlier in the day with a median admit time of 13:53 during phase 1. Once the transition beds were no longer open, the median admission time moved later in the day again to 16:01. 


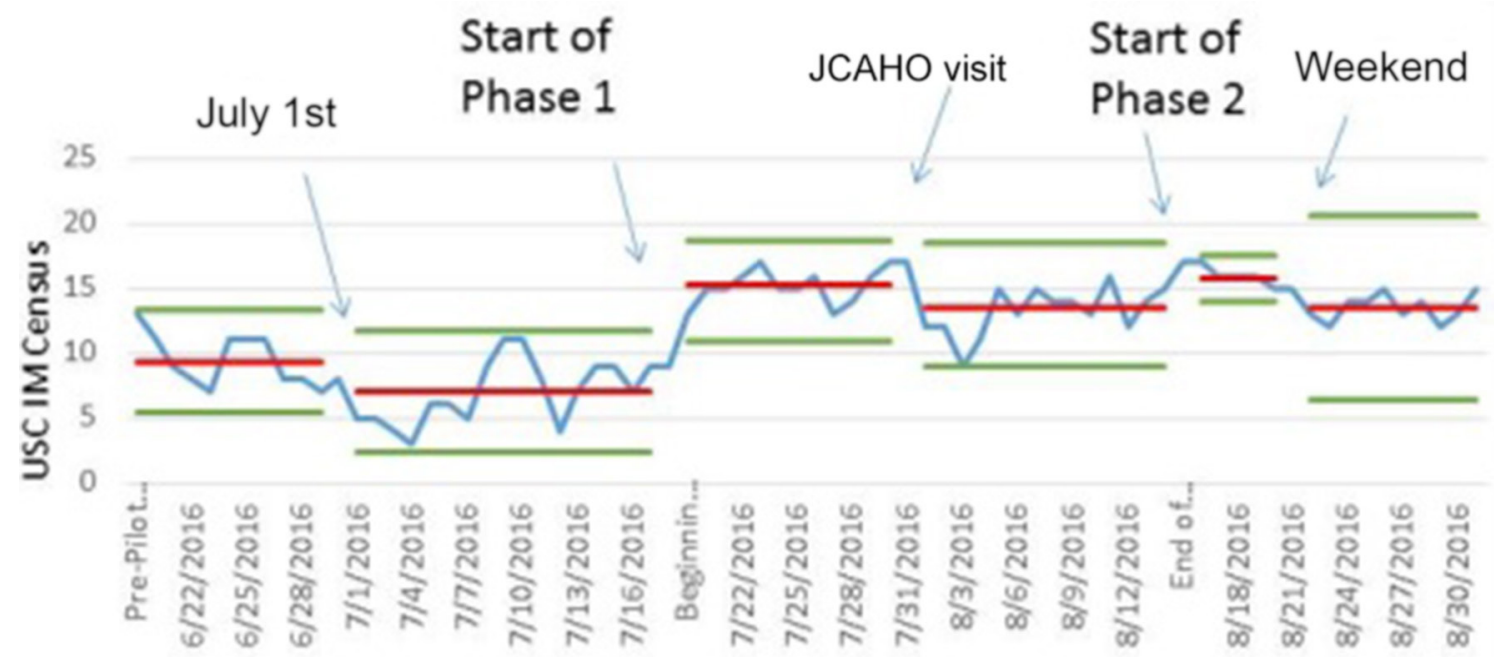

Figure 2 Control chart of USC IM census with key points marked. JCAHO, Joint Commission on Accreditation of Health Care Organizations; USC IM, University of South Carolina Internal Medicine Residency Program.

Patients were initially confused by the transition bed process, which was addressed with education to sending units (primarily the ED) through scripting. From the patients' perspective, it was difficult to see the benefit since they only saw a move to a hospital bed followed by another move to another bed. With the right framing, the overall impression of the process improved-patients were happy to be a part of a team-based, patient-centred unit.

The staff experience, outside of the charge nurses, was best summed up by one of our attendings who said the APP was 'a resounding success'. In general, the responses were positive. Physicians and nurses both appreciated having more USC IM patients on the unit. The comments mostly focused on perceived greater comradery and work efficiency. The workload varied for nurses assigned to the suite but peak days by all accounts were manageable.

Most of the burden in coordinating the throughput fell on the charge nurses, and there was significant stress some days. While staffing levels were maintained fairly well, busy days meant the newly added coordination effort was more onerous and readily identified (fairly or not) as a point of frustration.

\section{LESSONS AND LIMITATIONS}

The transition beds made a clear difference, but ultimately we were not able to continue using them primarily because of the burden we were placing on charge nurses who felt inadequately prepared to handle the constantly evolving change processes. We realised we must begin to plan all of our care processes around the charge nurses who are truly the hub of a team-based unit. While one high-functioning charge nurse was involved in planning and a proponent of the work, our other charge nurses grew increasingly frustrated. Their frustration was the main reason we decided to discontinue the transition beds.

Multiple factors contributed to their frustration including the perception of understaffing, high staff

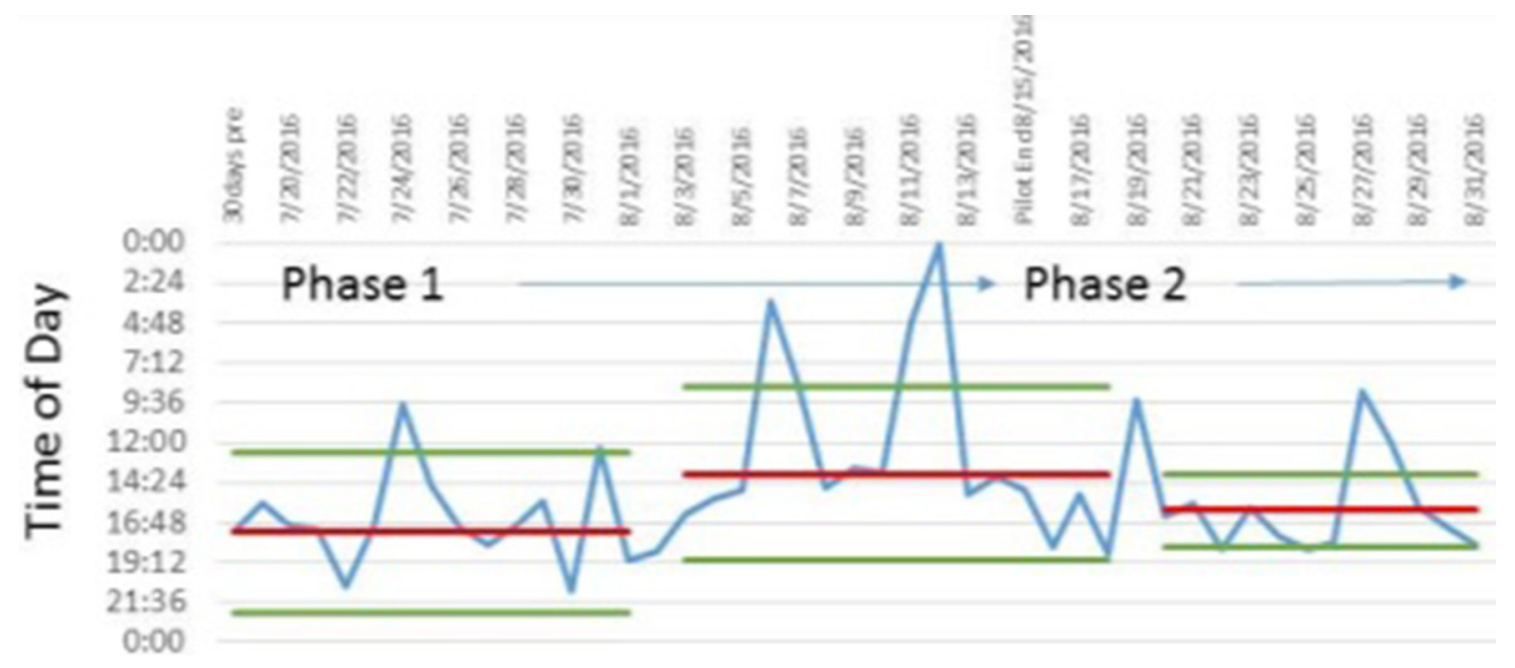

Figure 3 Control chart of median admission time with phases marked. 
turnover, as well as constant state of change in the hospital. We shared all of these concerns openly with hospital administration and have been able to modify our training for charge nurses to better prepare them for their leadership role.

Notably, one factor in particular that came across in interviewing our charge nurses was the challenge in starting another large-scale pilot (initiated from elsewhere in our hospital system) in the middle of this particular pilot on patient placement. While change is certainly the norm in healthcare, the new pilot began to demand more time and add to the growing frustration on the part of our charge nurses. This was a major contributing factor in our decision to discontinue the transition beds when the additional staffing for the APP ended. Our unit leadership became more vocal about the problem of inadequate communication between different departments, and we have seen improvement since the time of this pilot.

For units considering this sort of work, two unique contextual factors worth acknowledging for generalisability purposes are staffing and bed assignment. We relied on an internal nurse staffing pool (essentially nurses on call) to help our unit expand nurse staffing capacity. While transition beds could be used with existing staffing levels, the process adds an additional element of complexity such that the additional staffing support was crucial for nursing leadership buy-in to get the project off the ground. Also, if a unit were to undertake this approach without being able to open additional beds, it may be more of a challenge to convince patient placement or hospital administration to move forward as it may be perceived as a decrease in beds available in the system.

\section{CONCLUSION}

Overall, the APP model made a difference: our USC IM census on $10 \mathrm{E}$ doubled to 15 , ED hold times decreased by 1 hour, admissions to the unit shifted earlier by 3.5 hours and patient/staff satisfaction was remarkably positive. We were able to successfully implement this pilot that involved the fairly novel idea of transition beds to aid with throughput for our unit. Due to workload concerns among our charge nurses, we did not continue with the transition beds, and we subsequently saw a decline in our census strengthening the conclusion that the transition beds were the key to the improved census. There was much learning that took place through this project including the importance of transparent leadership and the prominent role of charge nurses in a team-oriented inpatient unit. We have translated these lessons into effective change with other projects and do feel that transition beds could be successfully implemented again on our unit or elsewhere with careful attention to the team members preparing to lead the change.

Acknowledgements The author wishes to thank the key hospital leaders who made this project successful: Jaycelyn Morant, Forrest Fortier and Harmony Robinson.

Contributors CWG was the sole author of the work although the entire improvement team was responsible for carrying out the work. SQUIRE 2.0 guidelines were used in drafting of this document.

Competing interests None declared.

Provenance and peer review Not commissioned; externally peer reviewed.

Open Access This is an Open Access article distributed in accordance with the Creative Commons Attribution Non Commercial (CC BY-NC 4.0) license, which permits others to distribute, remix, adapt, build upon this work non-commercially, and license their derivative works on different terms, provided the original work is properly cited and the use is non-commercial. See: http://creativecommons.org/ licenses/by-nc/4.0/

(C) Published by the BMJ Publishing Group Limited. For permission to use (where not already granted under a licence) please go to http://www.bmj.com/company/ products-services/rights-and-licensing/

\section{REFERENCES}

1. Stein J, Murphy D, Payne C, et al. A remedy for fragmented hospital care: Harvard Business Review, 2017. https://hbr.org/2013/11/aremedy-for-fragmented-hospital-care (accessed 4 Mar 2017).

2. Agency for Healthcare Research and Quality. Improving patient flow and reducing emergency department crowding: a guide for hospitals, 2017. https://www.ahrq.gov/sites/default/files/publications/files/ ptflowguide.pdf (accessed 4 Mar 2017).

3. The Joint Commission Perspectives. New and revised requirements for patient flow through the ED. 2012;32 http://www.jointcommission. org/assets/1/6/stds_rev_patient_flow.pdf 